\title{
DA SUCESSÃO LEGÍTIMA DO COMPANHEIRO APÓS A DECLARAÇÃO DE INCONSTITUCIONALIDADE DO ARTIGO 1.790 DO CÓDIGO CIVIL BRASILEIRO.
}

\section{THE LEGITIMATE SUCCESSION OF THE PARTNER AFTER THE DECLARATION OF UNCONSTITUTIONALITY OF THE ARTICLE 1790 OF THE BRAZILIAN CIVIL CODE.}

\author{
Jhonny Matos dos Santos ${ }^{1}$ \\ Vanuza Pires da Costa ${ }^{2}$
}

Fábio Araújo Silva ${ }^{3}$

\section{RESUMO}

A entidade familiar faz-se presente em nossa sociedade desde a antiguidade; e, tendo esta evoluído ao longo das décadas, o ordenamento jurídico buscou regular este convívio. Fato é que a união estável é recente, se comparada ao casamento. Em maio de 2017, o Supremo Tribunal Federal, em matéria de direito sucessório, entendeu ser inconstitucional o artigo 1790 do Código Civil de 2002, fixando tese de repercussão geral (temas 498 e 809), no sentido de ser aplicado ao companheiro quando da sucessão, o artigo 1829 da mesma lei infraconstitucional. Neste trabalho, pretende-se demonstrar os motivos que levaram o STF a este entendimento, demonstrar as consequências dessa equiparação entre companheiros e cônjuges; bem como analisar a maneira de interpretar este dispositivo em favor do companheiro pelos tribunais deste país a partir de então. Ao final, busca-se evidenciar pela pesquisa realizada, o quão importante fora essa decisão do Supremo para os conviventes em união estável e a segurança jurídica que esta interpretação possui para esta forma de entidade familiar. A elaboração deste artigo fora pautado na pesquisa teórica tendo em vista a ampla possibilidade de referencial teórico e embasamento jurídico acerca do tema proposto, sendo utilizado o método dedutivo e pesquisa qualitativa em sua elaboração.

1 Bacharel em Direito pelo Centro Universitário Unirg. E-mail: ihonizin01@gmail.com

2 Especialista (Pós-Graduação Lato Sensu) em Direito do Trabalho e Processo do Trabalho pela Faculdade ITOP. Professora efetiva de Processo Civil e Prática Forense Civil do Curso de Direito do Centro Universitário Unirg. Professora de Processo Civil e Prática Forense Civil do curso de Direito da Faculdade UNEST. Advogada. E-mail: vanuzapires.adv@gmail.com

3 Mestre em Produção Vegetal pela Universidade Federal do Tocantins. Pós-Graduado em Direito Tributário pela UNISUL. Pós-Graduado em Ciências Penais pela Faculdade Anhanguera. Pós-Graduado em Direito Público pela Faculdade Anhanguera. Professor no Curso de Direito do Centro Universitário Unirg. Advogado, Conciliador Judicial na Comarca de Figueirópolis. E-mail: fabiosilva2020@yahoo.com.br 
Palavras-chave: Casamento. Equiparação. União estável. Sucessão. STF.

\begin{abstract}
The family entity has been present in our society since antiquity; and, having evolved over the decades, the legal system sought to regulate this conviviality. The fact is that the stable union is recent compared to marriage. In May 2017, the Federal Supreme Court, in terms of inheritance law, considered that article 1790 of the Civil Code of 2002 was unconstitutional, establishing a thesis of general repercussion (items 498 and 809), in the sense of being applied the article 1829 of the same infraconstitutional law, to the partner during the succession. In this work, we intend to demonstrate the reasons that led the Brazilian Supreme Court to this understanding, to demonstrate the consequences of this equation between partners and spouses; as well as examine how to interpret this device in favor of the partner by the courts of this country from then on. Finally, it is sought to show by the research carried out how this decision of the Brazilian Supreme Court was important for the cohabitants in a stable union and the legal certainty that this interpretation has for this form of family entity. The elaboration of this article was based on theoretical research in view of the wide possibility of theoretical reference and legal basis on the proposed theme, using the deductive method and qualitative research in its elaboration.
\end{abstract}

Keywords: Marriage. Equalization. Stable union. Succession. Federal Supreme Court.

\title{
INTRODUÇÃO
}

Considerando que a união estável seja uma forma de entidade familiar, devendo ela ser protegida pelo ordenamento jurídico vigente, o Supremo Tribunal Federal em 10 de maio de 2017, com base no julgamento de dois Recursos Extraordinários (REs) 646.721 e 878.694, firmou tese de repercussão geral no sentido de declarar inconstitucional o art. 1.790 CC/2002, pugnando pela aplicação do art. 1.829 do mesmo Código quando do direito sucessório do companheiro.

Referido entendimento se coaduna com o do constituinte de 1988 que, ao elaborar a Magna Carta, dispôs no artigo 226, §3², que "para efeito da proteção do 
Estado, é reconhecida a união estável entre homem e mulher como entidade familiar, devendo a lei facilitar sua conversão em casamento."

Neste eito, torna-se evidente que a lei infraconstitucional, a exemplo do Código Civil de 2002 em seu artigo 1.790, não legislou em concordância com a Constituição Federal de 1988, quando da parte de Direitos sucessórios do companheiro, tendo ele sofrido diferenciação em relação á divisão dos bens do falecido aos respectivos herdeiros, não estando o companheiro sequer no rol dos herdeiros necessários.

Antes mesmo desse novo entendimento da Suprema Corte, alguns autores já alertavam para essa desigualdade existente entre companheiros e cônjuges para 0 direito sucessório, a qual se encontra regulamentada pelo Código Reale.

Tendo em vista as breves considerações feitas a respeito do tema, não restam dúvidas sobre a importância deste novo entendimento do STF, equiparando companheiro e cônjuge para fins sucessórios. Resta saber, qual o impacto que o referido posicionamento terá nas relações familiares existentes, o qual merece uma análise mais crítica no decorrer deste artigo.

\section{MATERIAIS E MÉTODOS}

Será utilizado no presente artigo o método dedutivo, isto é, pesquisa bibliográfica, tendo em vista a ampla possibilidade de referencial teórico e embasamento jurídico acerca do tema proposto. Bem como a pesquisa qualitativa, de forma a compreender os direcionadores desse entendimento do STF para o direito sucessório brasileiro.

O referido artigo terá embasamento em julgados das Cortes Superiores, sites, artigos científicos, doutrinas, súmulas, leis infraconstitucionais e legislação constitucional, sempre direcionados para o tema da união estável frente o Direito Sucessório. 


\section{RECURSOS EXTRAORDINÁRIOS (RE 646.721 E RE 878.694) E OS PRINCIPAIS MOTIVOS QUE LEVARAM Á DECLARAÇÃO DE INCONSTITUCIONALIDADE DO ARTIGO 1.790 DO CÓDIGO CIVIL.}

No dia 10 de maio de 2017, o Supremo Tribunal Federal fixou entendimento de repercussão geral que declarou ser inconstitucional o art. 1.790 do Código Civil de 2002.

Referido entendimento passou a declarar que "é inconstitucional a distinção prevista no art. 1.790 do CC/2002, devendo ser aplicado, tanto nas hipóteses de casamento quanto nas de união estável, o regime do art. 1.829 do CC/2002." Conforme relatoria do Min. Roberto Barroso:

Decisão: O Tribunal, apreciando o tema 809 da repercussão geral, por maioria e nos termos do voto do Ministro Relator, deu provimento ao recurso, para reconhecer de forma incidental a inconstitucionalidade do art. 1.790 do CC/2002 e declarar o direito da recorrente a participar da herança de seu companheiro em conformidade com o regime jurídico estabelecido no art. 1.829 do Código Civil de 2002, vencidos os Ministros Dias Toffoli, Marco Aurélio e Ricardo Lewandowski, que votaram negando provimento ao recurso. Em seguida, o Tribunal, vencido o Ministro Marco Aurélio, fixou tese nos seguintes termos: "É inconstitucional a distinção de regimes sucessórios entre cônjuges e companheiros prevista no art. 1.790 do CC/2002, devendo ser aplicado, tanto nas hipóteses de casamento quanto nas de união estável, o regime do art. 1.829 do CC/2002". Ausentes, justificadamente, os Ministros Dias Toffoli e Celso de Mello, que votaram em assentada anterior, e, neste julgamento, o Ministro Luiz Fux, que votou em assentada anterior, e o Ministro Gilmar Mendes. Não votou o Ministro Alexandre de Moraes, sucessor do Ministro Teori Zavascki, que votara em assentada anterior. Presidiu o julgamento a Ministra Cármen Lúcia. Plenário, 10.5.2017. (RE 878694 RG, Relator(a): Min. ROBERTO BARROSO, julgado em 16/04/2015, PROCESSO ELETRÔNICO DJe092 DIVULG 18-05-2015 PUBLIC 19-05-2015 )

Este entendimento nasce das inúmeras controvérsias geradas nos julgamentos realizados pelos Tribunais deste país; em que havia a diferenciação, senão a discriminação, do regime escolhido pelos pares, em uniões hetero ou homoafetivas, para instituírem suas famílias. 
Flávio Tartuce (2016, pág.1549), já se manifestava acerca dessa problemática enfrentada nos tribunais. Segundo ele, "a variação dos entendimentos dos julgados demonstra o sistema caótico existente no Brasil quanto á sucessão legítima. A constatação é que a Torre de Babel não é apenas doutrinária, mas também jurisprudencial."

Dentre esses julgados, dois mereceram atenção especial do STF, pondo fim á discussão que muitos doutrinadores levantavam em relação ao tema, já indicando que tal dispositivo legal seria inconstitucional. Os Recursos Extraordinários RE 646.721 e RE 878.694, respectivamente:

UNIÃO ESTÁVEL - COMPANHEIROS - SUCESSÃO - ARTIGO 1.790 DO CÓDIGO CIVIL - COMPATIBILIDADE COM A CONSTITUICÃ̃O FEDERAL ASSENTADA NA ORIGEM - RECURSO EXTRAORDINÁRIO - REPERCUSSÃO GERAL CONFIGURADA. Possui repercussão geral a controvérsia acerca do alcance do artigo 226 da Constituição Federal, nas hipóteses de sucessão em união estável homoafetiva, ante a limitação contida no artigo 1.790 do Código Civil. (RE 646721 RG, Relator(a): Min. MARCO AURÉLIO, julgado em 10/11/2011, ACÓRDÃO ELETRÔNICO DJe-232 DIVULG 06-12-2011 PUBLIC 07-12-2011)

Ementa: DIREITO DAS SUCESSÕES. RECURSO EXTRAORDINÁRIO. DISPOSITIVOS DO CÓDIGO CIVIL QUE PREVEEM DIREITOS DISTINTOS AO CÔNJUGE E AO COMPANHEIRO. ATRIBUIÇÃO DE REPERCUSSÃO GERAL. 1. Possui caráter constitucional a controvérsia acerca da validade do art. 1.790 do Código Civil, que prevê ao companheiro direitos sucessórios distintos daqueles outorgados ao cônjuge pelo art. 1.829 do mesmo Código. 2. Questão de relevância social e jurídica que ultrapassa os interesses subjetivos da causa. 3 . Repercussão geral reconhecida. (RE 878694 RG, Relator(a): Min. ROBERTO BARROSO, julgado em 16/04/2015, PROCESSO ELETRÔNICO DJe-092 DIVULG 18-05-2015 PUBLIC 19-05-2015 )

Há que se observar, frente o tema objeto desta repercussão geral o que diz a Constituição Federal de 1988 em seu artigo 226, §3º que "para efeito de proteção do 
Estado, é reconhecida a união estável entre o homem e a mulher como entidade familiar, devendo a lei facilitar sua conversão em casamento."

Porém, considerando a ulterioridade do Código Civil brasileiro frente à Constituição, o que se conclui é que o legislador quando da elaboração daquela não conseguiu alcançar a finalidade da norma Constitucional, dando interpretação diversa da que se destinava.

Diante do artigo da CF/88 mencionado, no julgamento pelo Pleno destes recursos, muito se discutiu a cerca dos princípios constitucionais violados, os quais entre outros, fica evidenciado serem o princípio da igualdade, da dignidade humana e a vedação ao retrocesso.

Dentre aos princípios citados acima, o da igualdade e o da vedação ao retrocesso merecem certa consideração para que se possa entender a decisão do Supremo.

\subsection{PRINCÍPIO DA IGUALDADE}

Alexandre de Moraes pondera ter o princípio da igualdade uma tríplice finalidade limitadora. Sendo que para o caso em questão, há de serem observadas as limitações impostas ao legislador e ao intérprete/ autoridade pública.

[...] O legislador, no exercício de sua função constitucional de edição normativa, não poderá afastar-se do princípio da igualdade, sob pena de flagrante inconstitucionalidade. Assim, normas que criem diferenciações abusivas, arbitrárias, sem qualquer finalidade lícita, serão incompatíveis com a Constituição Federal.

O intérprete/autoridade pública não poderá aplicar as leis e atos normativos aos casos concretos de forma a criar ou aumentar desigualdades arbitrárias. Ressalte-se que, em especial o Poder Judiciário, no exercício de sua função jurisdicional de dizer o direito ao caso concreto, deverá utilizar os mecanismos constitucionais no sentido de dar uma interpretação única e igualitária ás normas jurídicas. Nesse sentido a intenção do legislador constituinte ao prever o recurso extraordinário ao Supremo Tribunal Federal (uniformização na interpretação da Constituição Federal) [...]. Além disso, sempre em 
respeito ao princípio da igualdade, a legislação processual deverá estabelecer mecanismos de uniformização da jurisprudência a todos os tribunais. (MORAES, 2016, p. 37)

$\mathrm{O}$ art. 1.790 do CC/2002, que trata da sucessão do companheiro desiguala as entidades familiares que a $\mathrm{CF} / 88$ protege. $\mathrm{O}$ que entra em colisão com este princípio. Pois, a intenção do legislador constituinte ao incluir a união estável na Carta Magna foi de amparar esta entidade familiar que surgiu com a crescente evolução de comportamento da sociedade.

\subsection{PRINCÍPIO DA VEDAÇÃO AO RETROCESSO}

Mesmo não estando explícito em nossa Carta Magna, o presente princípio tem por finalidade garantir as conquistas sociais, frutos da evolução da sociedade brasileira. Em que pese ser as leis reguladoras de nossa sociedade, o legislador deve sempre observar o meio para atingir o fim em si.

Para Barroso,

Por este princípio que não é expresso, mas decorre do sistema jurídicoconstitucional, entende-se que se uma lei, ao regulamentar um mandamento constitucional, instituir determinado direito, ele se incorpora ao patrimônio jurídico da cidadania e não pode ser arbitrariamente suprimido. Nessa ordem de ideias, uma lei posterior não pode extinguir um direito ou garantia, especialmente os de cunho social, sob pena de promover um retrocesso, abolindo um direito fundado na Constituição. $\mathrm{O}$ que se veda é o ataque á efetividade da norma, que foi alcançado a partir de sua regulamentação. (BARROSO, apud. Bühring, p. 60, 2015)

Podemos concluir através deste princípio, que o tratamento dispensado ao companheiro quando do direito sucessório, retrocedia a um estado no qual a união estável não possuía o status de entidade familiar. Trazendo com isso diferenciações que hoje não podem mais existir.

Antes da entrada em vigor do atual Código Civil e consequentemente da aplicação do art. 1.790 aos casos concretos, após a Constituição Federal de 1988, 
foram publicadas as leis 8.971/94 e 9.278/96 que regulamentavam o direito sucessório do companheiro.

A lei 8.971/94, no que diz respeito a sucessão, protegia o direito de usufruto do companheiro enquanto não constituísse nova união, em concorrência com descendentes ou ascendentes, tendo o direito de gozar dos bens do companheiro falecido enquanto perdurasse esta condição.

O inciso III, do art. $2^{\circ}$ da lei acima citada, dava direito a herança ao companheiro em toda sua plenitude, caso não houvesse descendentes ou ascendentes para concorrer com aquele.

Porém, a publicação da lei 9.278/96 serviu para regular o que diz o parágrafo $3^{\circ}$ do art. 226 de nossa Carta Magna. Conforme o artigo $1^{\circ}$ desta lei, "É reconhecida como entidade familiar a convivência duradoura, pública e contínua, de um homem e de uma mulher, estabelecida com o objetivo de constituição de família". Conceituando o que se entende por entidade familiar formada através da união estável.

Esta lei dava ao companheiro sobrevivente direito real de habitação sobre o imóvel de cunho residencial desde que, fosse este destinado á habitação desta entidade familiar.

Com a promulgação do Código Civil vigente, estes direitos já concedidos aos companheiros sobreviventes relativos ao direito sucessório, foram revogados, tendo o legislador infraconstitucional suprimido direitos já conquistados pelo convivente, direito de usufruto e habitação; configurando assim, violação ao princípio da vedação ao retrocesso.

Dados todos esses embaraços interpretativos que o referido artigo possuía, quando da sua interpretação, a Suprema Corte deste país finalizou esta discussão. Devendo ser considerada a finalidade do art. $226, \S 3^{\circ}$ da CF/88 para que todos os Tribunais interpretem o direto sucessório do companheiro, de forma igualitária aos direitos do cônjuge. 
Entre estes dois institutos, conforme se verifica, não deve haver diferenciação ou maneiras de ser um mais importante que o outro, pois, se busca proteger na aplicação da norma ao caso concreto a entidade familiar, independente do regime que os envolvidos nesta relação tenham escolhido para conviver.

\section{A APLICAÇÃO DO ART. 1.829 DO CC/2002 AOS COMPANHEIROS}

Algumas questões merecem destaque antes que seja discorrido sobre a sucessão do companheiro e a consequente aplicação do art. 1.829 do CC/2002. Na vigência do Código Civil de 1916, o regime legal, no silêncio das partes, era o de comunhão universal de bens, diferentemente do que ocorre nos casamentos de hoje em dia que, no silêncio dos nubentes, prevalecerá o regime de comunhão parcial de bens.

Sendo o regime de comunhão universal adotado no casamento, o cônjuge sobrevivo não era herdeiro, porém meeiro, haja vista que pelo regime adotado, confundia-se o seu patrimônio com o do falecido, tornando-se apenas um.

Quando em 1977, com a promulgação da Lei do Divórcio (lei 6.515/77), houve alteração do artigo que regulava o regime geral de casamento, passando este não mais ser o de comunhão universal, tendo como regime geral a partir de então, a comunhão parcial de bens, que no Código Civil vigente á época, passou o artigo 258 CC/1916 caput, ter a seguinte redação; "Não havendo convenção, ou sendo nula, vigorará, quanto aos bens entre os cônjuges, o regime de comunhão parcial".

Outra questão a ser analisada do CC/1916, era a ordem sucessória do cônjuge quando da sucessão. Diferentemente do que ocorre nos dias atuais, aquele, na linha sucessória, apresentava-se em terceiro lugar na ordem da vocação hereditária.

Porém, com o início da vigência da Lei do Divórcio, e tendo o regime geral de casamento sido alterado, houve a necessidade de proteger os direitos do cônjuge. Fato é que, com a promulgação do Código Civil atual, o legislador buscou proteger o direito 
sucessório daquele, incluindo-o como herdeiro necessário, além de colocá-lo em concorrência com os demais herdeiros, descendentes e ascendentes.

Conforme é demonstrado, houve a preocupação do legislador infraconstitucional de proteger o cônjuge, não tendo ocorrido o mesmo para os companheiros em união estável. Ficando estes prejudicados, pela simples razão de terem escolhido esta forma de convivência entre os regimes existentes do instituto familiar.

Após a declaração de inconstitucionalidade pelo STF do artigo 1.790 do CC/2002, que legislava sobre o direito sucessório do companheiro, cumpre agora analisar a aplicação do art. 1.829 do Código em tela para estes.

Em que pese o reconhecimento desta inconstitucionalidade datar de maio de 2017, os efeitos desta decisão terão eficácia apenas para os inventários judiciais ainda pendentes de trânsito em julgado ou caso o inventário seja extrajudicial, se ainda não tiver sido feita a escritura pública deste.

Cumpre salientar que tal medida adotada após este entendimento, tem como premissa a segurança jurídica. Para que das decisões que acolheram o entendimento do art. 1.790 quando da aplicação ao companheiro no direito sucessório e tendo estas já transitado em julgado, não possa o mesmo processo ser discutido novamente.

Portanto, deve nossa Constituição não somente reconhecer os dispositivos infraconstitucionais que com ela não possuem nexo, como também assegurar o direito adquirido e a coisa julgada daquele que dentro do nosso sistema jurídico vigente logrou êxito em determinada demanda levada a conhecimento dos tribunais deste país, quando ainda determinado dispositivo era possível sua aplicação.

Dada essas considerações iniciais acerca da efetividade do entendimento adotado pela Suprema Corte deste país, é necessário que entendamos a aplicação do art. 1.829 do CC/2002 aos companheiros.

De acordo com o art. 1829, 
A sucessão legítima defere-se na ordem seguinte:

I - aos descendentes, em concorrência com o cônjuge sobrevivente, salvo se casado este com o falecido no regime da comunhão universal, ou no da separação obrigatória dos bens (art. 1.640, parágrafo único); ou se, no regime da comunhão parcial o autor da herança não houver deixado bens particulares;

II - aos ascendentes, em concorrência com o cônjuge;

III - ao cônjuge sobrevivente;

IV- aos colaterais. (BRASIL, 2002)

Sabendo-se da aplicação deste artigo aos companheiros, passaremos a análise do mesmo utilizando o companheiro sobrevivo na análise dos incisos I a III deste artigo.

\subsection{CONCORRÊNCIA DO COMPANHEIRO COM OS DESCENDENTES}

Em relação ao inciso I do artigo 1.829, o companheiro passou a ter direito de herdar sobre os bens particulares do companheiro falecido, tenham sido eles obtidos a título oneroso ou gratuito. O que quando da aplicação do artigo 1.790 isso não era possível, haja vista seu direito de herança estar restrito apenas aos bens adquiridos onerosamente com a participação de ambos na constância da união.

Então, é de imaginar-se a seguinte situação; o companheiro quando ainda vivo herdou ou recebeu através de doação determinados bens que somados ultrapassam o valor dos que construiu com sua companheira.

Diante da atual situação, em melhor posição se encontra a companheiro sobrevivo atualmente, pois, quando da partilha dos bens do falecido, esta será feita sobre um único monte-mor, englobando o patrimônio que estes construíram juntos (após a retirada de sua meação) e os bens particulares adquiridos a título oneroso ou gratuito apenas pelo falecido.

Diante da aplicação deste inciso há que se observar que para os companheiros não possui um regime específico que normatize esta união como ocorre no casamento. Porém, de acordo com o art.1.725 CC/2002 "Na união estável, salvo contrato escrito entre os companheiros, aplica-se ás relações patrimoniais, no que couber, o regime da 
comunhão parcial de bens", o que, atinge a finalidade do presente inciso, equiparando companheiros e cônjuges, em suas relações de união ou casamento.

\subsection{CONCORRÊNCIA DO COMPANHEIRO COM OS ASCENDENTES}

Aqui encontrava-se a maior desigualdade sucessória destinada ao companheiro. Conforme o inciso III do art. 1.790 do CC, "se concorrer com outros parentes sucessíveis, terá direito a um terço da herança", vale ressaltar que nestes "outros parentes sucessíveis" do dispositivo declarado inconstitucional, estavam englobados todos os parentes, ascendentes ou colaterais, até quarto grau, da linha sucessória do companheiro falecido.

Em análise do dispositivo em questão, podemos observar que os colaterais eram equiparados ao ascendente quando da sucessão na união estável, o que não ocorre na sucessão do cônjuge sobrevivo. Haja vista os mesmos apenas herdarem caso o falecido não tenha deixado em sua linha sucessória descendentes, ascendentes ou cônjuge, por serem estes herdeiros necessários, conforme preceitua o art. 1.845 do $\mathrm{CC} / 2002$.

De toda sorte, em melhor posição está o companheiro com a aplicação do inciso II do art. 1829 do CC, visto que, a partilha da herança deste se dará obedecendo a linha sucessória. E quando houver de partilhar apenas com os ascendentes, caso estes já sejam falecidos ou estiverem impedidos de receber a legítima, herdará o companheiro na totalidade o monte-mor, devendo o colateral apenas herdar caso este também esteja falecido ou impedido.

\subsection{COMPANHEIRO SOBREVIVENTE}

Conforme já exposto no tópico anterior sobre o errôneo dispositivo legal ao mencionar "outros parentes sucessíveis", sendo o art. 1.829 CC/2002 aplicado quando houver direito do companheiro a herança, este terá preferência em relação ao colateral na linha sucessória. 
Pois, através da nova forma de sucessão estabelecida ao companheiro, tendo deixado de concorrer com os colaterais, este herdará na totalidade, se, quando da abertura da sucessão, não mais existirem descendentes ou ascendentes, devendo os possíveis colaterais em linha sucessória, herdar em quarto lugar, se ausentes descendentes, ascendentes ou o companheiro, diante da aplicação do art. 1.829 CC/2002.

Fato é que, em março de 2018, o Superior Tribunal de Justiça com base nesta tese de repercussão geral ora em contento, negou provimento por unanimidade ao Recurso Especial 1.357.117-MG, afirmando ter o companheiro preferência na concorrência sucessória com os colaterais.

Tendo o acórdão a seguinte ementa:

RECURSO ESPECIAL. CIVIL. PROCESSUAL CIVIL. DIREITO DE FAMÍLIA E DAS SUCESSÕES. UNIÃO ESTÁVEL. ART. 1.790 DO CC/2002. INCONSTITUCIONALIDADE. ART. 1.829 DO CC/2002. APLICABILIDADE. VOCAÇÃO HEREDITÁRIA. PARTILHA. COMPANHEIRO. EXCLUSIVIDADE. COLATERAIS. AFASTAMENTO. ARTS. 1.838 E 1.839 DO CC/2002. INCIDÊNCIA. 1. Recurso especial interposto contra acórdão publicado na vigência do Código de Processo Civil de 1973 (Enunciados Administrativos nos 2 e 3/STJ). 2. No sistema constitucional vigente, é inconstitucional a distinção de regimes sucessórios entre cônjuges e companheiros, devendo ser aplicado em ambos os casos o regime do artigo 1.829 do CC/2002, conforme tese estabelecida pelo Supremo Tribunal Federal em julgamento sob o rito da repercussão geral (Recursos Extraordinários nos 646.721 e 878.694). 3. $\mathrm{Na}$ falta de descendentes e ascendentes, será deferida a sucessão por inteiro ao cônjuge ou companheiro sobrevivente, ressalvada disposição de última vontade. 4. Os parentes colaterais, tais como irmãos, tios e sobrinhos, são herdeiros de quarta e última classe na ordem de vocação hereditária, herdando apenas na ausência de descendentes, ascendentes e cônjuge ou companheiro, em virtude da ordem legal de vocação hereditária. 5. Recurso especial não provido. (REsp 1357117 RG, Relator(a): Min. RICARDO VILLAS BÔAS CUEVA, julgado em 13/03/2018, ACÓRDÃO ELETRÔNICO DJe-1061 DIVULG 23-03-2018 PUBLIC 26-03-2018) 


\section{O COMPANHEIRO COMO HERDEIRO NECESSÁRIO}

Tendo o companheiro após anos de desigualdade, conquistado a equiparação ao cônjuge para que possa concorrer com os descendentes ou ascendentes e tendo preferência em face dos colaterais no que diz respeito a herança, há que se considerar ser ele incluído também no rol dos herdeiros necessários. Conforme preceitua o art. 1.845 CC/2002 "São herdeiros necessários os descendentes, ascendentes e o cônjuge".

Em preliminares, cumpre observar a diferença entre o herdeiro legítimo e o herdeiro necessário. Para Washington de Barros Monteiro apud Gonçalves, "Todo herdeiro necessário é legítimo, mas nem todo herdeiro legítimo é necessário". (pág. 206, 2011)

Ainda sobre os herdeiros necessários, de acordo com Giselda Hironaka, apud Gonçalves (2011), não pode o sucedido afastar os herdeiros necessários por sua simples vontade, salvo terem eles praticado atos que os levem a deserdação.

Em fevereiro de 2018, o Instituto Brasileiro de Direito de Família (IBDFAM) opôs embargos de declaração contra acórdão da decisão que equiparou cônjuge e companheiro para fins sucessórios. Aduz ainda o referido instituto que há a necessidade de o Ministro relator do processo se manifestar em relação a extensão dessa decisão para o companheiro, visto o entendimento mencionar apenas a aplicação do art. $1.829 \mathrm{CC} / 2002$ para estes.

Há que se observar a finalidade da decisão; qual fora, como já mencionado ao longo deste artigo, a proteção dos que escolheram a união estável como forma de entidade familiar, devendo a lei protegê-los da mesma forma como o faz com os que vivem sob o regime do casamento.

É de se considerar que, a questão pode ser resolvida através da analogia, que para Paulo Nader (pág. 194, 2013), "é um recurso técnico que consiste em se aplicar; a uma hipótese não prevista pelo legislador, a solução por ele apresentada para uma hipótese fundamentalmente semelhante a não prevista". 
Sendo o cônjuge herdeiro necessário, entende-se ter o companheiro a mesma garantia, visto a Suprema Corte ter se manifestado no sentido de serem as entidades familiares formadas pelo casamento ou união estável equivalentes para fins sucessórios. Devendo a este, ser assegurado a parte da herança a qual faz jus, assim como o é para os descendentes e na ausência destes os ascendentes.

\section{CONSIDERAÇÕES FINAIS}

O intérprete da lei possui extrema relevância para que sua finalidade seja alcançada. E após esta nova maneira interpretativa da sucessão do companheiro, este poderá aplicá-la igualmente tanto aos cônjuges como aos conviventes em união estável, garantindo-Ihes a segurança jurídica de um futuro por vezes incerto.

O que se entende desta decisão do Supremo, é que houve uma ponderação de valores que a Constituição garante, ao passo que o Código Civil em seu artigo declarado inconstitucional vedava. Há que se entender que a Carta Magna protege as diversas formas de entidade familiar o que o art. 1.790 CC/2002 não atingia esta finalidade, sendo interpretado de maneira a proteger apenas o patrimônio dos companheiros.

Como consequência deste entendimento, observa-se que as pessoas ficaram livres para escolher em qual entidade do instituto familiar desejam formar suas famílias. Pouco importando quando do direito sucessório, ser estas relações formadas através casamento ou pela simples vontade das partes de conviverem em união estável, visto estarem elas igualmente protegidas por nosso ordenamento jurídico.

Hoje, não mais podendo haver essa discriminação entre as entidades familiares, espera-se desta decisão quando tratar-se de direito sucessório do companheiro este não apenas tenha direito a concorrer na linha sucessória como se cônjuge fosse, mas também ser ele equiparado a este na interpretação de outros dispositivos deste livro do Código Civil. 
A exemplo disso, espera-se que este entendimento seja estendido aos demais artigos do direito sucessório, devendo o companheiro ter direito a legítima, assim como os herdeiros necessários prescritos no art. 1.845 o tem, como também possa ter ele direito real de habitação, assegurado ao cônjuge na sucessão.

\section{REFERÊNCIAS}

BRASIL. Câmara dos Deputados. Projeto preserva direito de companheiro viúvo morar na casa da família. Direito e Justiça. 2018. \{Notícias\}. Disponível em: $<$ http://www2.camara.leg.br/camaranoticias/noticias/DIREITO-E-JUSTICA /538291PROJETO-PRESERVA-DIREITO-DE-COMPANHEIRO-VIUVO-MORAR-NA-CASA-DAFAMILIA.html>. Acesso em: 20 de abril de 2018.

. LEI 3.071/1916, DE 1 DE JANEIRO DE 1.916. Código Civil dos Estados Unidos do Brasil. Rio de Janeiro, RJ, Jan 1916. Disponível em: <http://www.planalto.gov.br/ccivil 03/Leis/L3071.htm>. Acesso em: 14 de abril de 2018.

. Supremo Tribunal Federal. Julgamento afasta a diferença entre conjugue e companheiro para fim sucessório. Brasília-DF. FT/CV. 2017. \{Notícias\}. Disponível em: <http://www.stf.jus.br/portal/cms /ver Noticia Detalhe.asp?idConteudo=342982>. Acesso em: 31 de março de 2018.

BÜHRING, Márcia Andrea. Direito Social: proibição de retrocesso e dever de progressão. Direito \& Justiça, Porto Alegre, v. 41, n. 1, p. 56-73, jan.-jun. 2015. ISSN 0100-9079. Disponível em: <http://revistaseletronica s.pucrs.br/ojs/index.php/fadir/article/view/18175/12667>. Acesso em 31 de março de 2018. doi: http://dx.doi.org/10.15448/1984-7718.2015.1.18175.

DA SILVA, Rogerio Luiz Nery; DOS SANTOS, Cristiane Brum. Reflexos da proibição de retrocesso na efetividade dos direitos sociais: limites aos limites dos direitos sociais na deflagração de crise econômica. Revista Brasileira de Direito, Passo Fundo, v. 13, n. 2, p. 120-136, ago. 2017. ISSN 2238-0604. Disponível em: $<$ https://seer.imed.edu.br/index.php/revistadedireito/article/view/1515/1190>. Acesso em: 31 de março de 2018. doi:https://doi.org/10.18256/22380604/revistadedireito.v13n2p120-136.

GONÇALVES, Carlos Roberto. Direito Civil Brasileiro, Volume 7: direito das sucessões - 5 edição - São Paulo, Editora Saraiva, 2011. 
INSTITUTO BRASILEIRO DE DIREITO DE FAMÍLIA. Em matéria de Direito Sucessório, companheiro assume a mesma posição do cônjuge, diz especialista. Disponível em: $<$ http://www.ibdfam.org. br/noticias/6585/Em+mat\%C3\%A9ria+de+Direito+Sucess\%C3\%B3rio\%2C+companheir o+assume+a+mesma+posi $\% \mathrm{C} 3 \% \mathrm{~A} 7 \% \mathrm{C} 3 \% \mathrm{~A} 30+\mathrm{do}+\mathrm{c} \% \mathrm{C} 3 \% \mathrm{~B} 4 \mathrm{njuge} \% 2 \mathrm{C}+$ diz+especial ista\%22>. Acesso em: 20 de abril de 2018.

. Instituto protocolou no STF embargos de declaração sobre concorrência sucessória cônjuge-companheiro. Disponível em: < http://www.ibdfam.org.br/notici as/6540/IBDFAM+protocolou+no+STF+embargos+de+declara\%C3\%A7\%C3\%A30+sob re+concorr\%C3\%AAncia+sucess\%C3\%B3ria+c\%C3\%B4njuge-companheiro>. Acesso em: 20 de abril de 2018.

. PL do IBDFAM em tramitação na Câmara é desarquivado. Disponível em: $<$ http://www.ibdfam.org.br/noticias/5543/PL+do+|BDFAM+em+tramita\%C3\%A7\%C3\%A 3o+na+C\%C3\%A2mara+\%C3\%A9+desarquivado>. Acesso em: 20 de abril de 2018.

MORAES, Alexandre de. Direito Constitucional. $32^{\circ}$ edição.- São Paulo, Editora Atlas, 2016.

NADER, Paulo. Introdução ao estudo do direito. $35^{\circ}$ edição - Rio de Janeiro, Editora Forense, 2013.

SARAIVA. Vade Mecum. 25ํㅡㄹ ed. atual. E ampl., São Paulo: Saraiva Educação, 2018.

TARTUCE, Flávio. STF encerra o julgamento sobre a inconstitucionalidade do art. 1.790 do Código Civil. E agora ?. Disponível em: <http://www.migalhas.com.br/ FamiliaeSucessoes/104,Ml259678,31047-

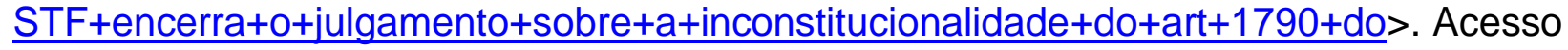
em 15 de março de 2018.

. Manual de direito civil: volume único. $6^{\mathrm{a}}$ ed. ver., atual. E ampl. - Rio de Janeiro, Ed. Forense; São Paulo, Ed. Método, 2016.

VENOSA, Sílvio de Salvo. Direito Civil: direito das sucessões $-13^{\circ}$ edição - São Paulo, Editora Atlas 2013. 